\title{
A TEMÁTICA AMBIENTAL NO ENSINO SUPERIOR: UM ESTUDO SOBRE A UNIVERSIDADE FEDERAL DE RONDÔNIA, CAMPUS DE PORTO VELHO
}

\author{
Clarides Henrich de Barba ${ }^{1}$ \\ Rosa Maria Feiteiro Cavalari ${ }^{2}$
}

\begin{abstract}
Resumo
Este artigo analisa a inserção da temática ambiental na Universidade Federal de Rondônia (Unir), campus de Porto Velho. Caracteriza-se como estudo de caso, tendo como instrumentos de coleta de dados: a análise documental dos projetos pedagógicos e dos planos das disciplinas de 14 cursos de graduação que desenvolvem a temática ambiental, entrevistas semidiretivas com os coordenadores e professores. A "análise de conteúdo" proposta por Bardin e as características de Ambientalização curricular elaboradas pela Rede Aces foram utilizadas na análise dos dados. Os resultados demonstram que os cursos estão ambientalizados ou em processo de Ambientalização curricular, sobretudo os de Geografia e Ciências Biológicas. Identificaram-se seis características de um currículo ambientalizado: compromisso com a transformação das relações sociedade-natureza, complexidade, contextualização local-globallocal global-local-global, levar em conta o sujeito na construção do conhecimento; considerar os aspectos cognitivos e afetivos, éticos e estéticos, espaços de reflexão e participação democrática, orientação prospectiva de cenários alternativos.
\end{abstract}

Palavras-chave: Ambientalização curricular. Temática ambiental. Educação ambiental.

\section{ENVIRONMENTAL THEME IN HIGHER EDUCATION: a case study at the University of Rondônia - Porto Velho Campus}

\begin{abstract}
This study analyzes the inclusion of the environmental theme at the Federal University of Rondônia (UNIR), Porto Velho campus. This is a "case study" based on documental analysis of the pedagogical projects and course planning of fourteen undergraduate courses that include environmental themes and "semi-directive" interviews with coordinators and teachers. The "content analysis" proposed by Bardin and the characteristics of the process of curricular "Greening" elaborated by the ACES Network were used for data analysis. The results reveal that the courses are "green" or in the process of curricular Greening, especially Geography and Biology courses. We observed six characteristics of a green curriculum: "commitment to the changes in society-nature relations", "complexity," "local-global-local and global-local-global contextualization," "consideration of cognitive and affective, ethical and aesthetic aspects", "opportunities for reflections and democratic participation," and prospective supervision of alternative scenarios."
\end{abstract}

\footnotetext{
${ }^{1}$ Doutor em Educação pela Universidade Estadual Paulista, Membro do Grupo de Pesquisa- EDUCA E CIEPES (Unir), Professor Associado do Departamento de Filosofia e credenciado pelos Programas de Pós Graduação: Mestrado em Educação- PPGE/UNIR, Mestrado Profissional em Educação- MEPE/UNIR- campus de Porto Velho, e-mail: clarides@unir.br

2 Doutora em Educação pela Universidade de São Paulo (1995) e Pós-Doutorado em Educação Ambiental na Chaire de Recherche du Canada en Éducation relative à l'environnement, da Université du Québec à Montréal (UQÀM) - (2010), Professora Assistente Doutora no Departamento de Educação e credenciada junto ao Programa de Pós-Graduação em Educação - Linha de Pesquisa: Educação Ambiental, do Instituto de Biociências UNESP - Universidade Estadual Paulista, campus de Rio Claro, email: rosamfc@rc.unesp.br.
} 
Keywords: Curricular greening. Environmental theme. Environmental Education.

\title{
LA TEMÁTICA AMBIENTAL EN LA ENSEÑANZA SUPERIOR: un estudio sobre la Universidad Federal de Rondônia, campus de Porto Velho
}

\begin{abstract}
Resumen
Este artículo analiza la inserción de la temática ambiental en la Universidad Federal de Rondônia (Unir), campus de Porto Velho. Se caracteriza como estudio de caso, presentando como instrumento de recolecta de dados: el análisis documental de los proyectos pedagógicos y de las asignaturas de 14 cursos de graduación que desarrollan la temática ambiental, entrevistas semidireccionales con los coordinadores y profesores. El "análisis de contenido" propuesto por Bardin y las características de Ambientalización curricular elaboradas por la Red Aces fueron utilizadas en el análisis de los datos. Los resultados demuestran que los cursos están ambientados o en proceso de Ambientalización curricular, sobre todo, los de Geografía y Ciencias Biológicas. Se identificaron seis características de un currículo ambientalizado: compromiso con la transformación de las relaciones sociedad-naturaleza, complejidad, contextualización local-global-local global-local-global; tener en cuenta el sujeto en la construcción del conocimiento, considerar los aspectos cognitivos y afectivos, éticos y estéticos; espacios de reflexión y participación democrática; orientación prospectiva de escenarios alternativos.
\end{abstract}

Palabras clave: Ambientalización curricular. Temática ambiental. Educación ambiental.

\section{Introdução}

A identificação de uma crise ambiental, sobretudo a partir do século XX, revela para as sociedades contemporâneas uma nova preocupação. Trata-se de uma preocupação com a natureza e com as relações que as sociedades atuais têm estabelecido. Essa preocupação se justifica tendo em vista uma série de transformações causadas pelo homens na natureza, como o aumento das fontes de emissão de poluição atmosférica, o desmatamento, e aquelas decorrentes do grande desenvolvimento científico e tecnológico, sobretudo nos países desenvolvidos que vem causando problemas ambientais de proporções planetárias. A identificação dessa crise e as tentativas de solução para os graves problemas ambientais resultaram em ações governamentais e não governamentais, além de se constituírem como objeto de estudo para cientistas e pesquisadores.

A compreensão a respeito da crise ambiental possibilitou aos pesquisadores das universidades investigarem a temática ambiental a partir de problemas caracterizados por questões epistemológicas, metodológicas, éticas e políticas. Estas investigações desencadearam reflexões nas Universidades, que resultaram em estudos a respeito da temática ambiental que aos poucos foi sendo inserida nos projetos pedagógicos dos diferentes cursos universitários.

No contexto histórico, foram realizados vários eventos científicos a respeito da temática ambiental no ensino superior. Assim, desde a Conferência Intergovernamental de Estocolmo (1977), as universidades passaram a incorporar a temática ambiental em seus currículos (LEFF, 1993; MERCADO, 2005; PAVESI, 2007). Dentre muitos eventos, destacam-se o $1^{\circ}$ Seminário sobre Universidade e Meio Ambiente na América Latina e Caribe, em 1985, que resultou na Carta de Bogotá sobre Universidade e Meio Ambiente; a Conferência Mundial sobre o Ensino Superior, realizada pela Unesco em 1988 na cidade de Paris. No Brasil, podemos ainda 
considerar a realização de quatro seminários com a temática "A universidade e o meio ambiente” em Brasília (1986), Belém (1987), Cuiabá (1989) e Florianópolis (1990), promovidos pela Secretaria Especial do Meio-ambiente (Sema) e pela Secretaria do Meio Ambiente do Estado de São Paulo. Do mesmo modo, a $1^{\text {a }}$ Conferência Nacional de Educação Ambiental, em 1997 comprovou a necessidade da incorporação da temática ambiental nos currículos do ensino superior.

A educação superior tem a incumbência de investigar, educar e formar para o desenvolvimento sustentável como um espaço aberto para a aprendizagem permanente, considerando quatro aspectos importantes:
- Considerar o ambiente em sua totalidade, tanto natural como o criado pelo homem com seus componentes ecológicos, políticos, econômicos e tecnológicos, sociais e legislativos, culturais e estéticos;
- Considerar a Educação Ambiental como um processo de toda a vida e não somente reduzida à escola;
- Orientar-se com um enfoque de totalidade e interdisciplinaridade;
- Colocar ênfase na participação ativa dos sujeitos para prevenir e resolver problemas ambientais, presentes e futuros (MERCADO, 1997, p. 216).

Tendo como referência esses aspectos, as universidades devem incorporar nos seus currículos conteúdos ambientais em disciplinas específicas ou em conteúdos interdisciplinares, de modo que os currículos contemplem conteúdos direcionados à justiça, aos direitos humanos, ao desenvolvimento sustentável, à democracia e à paz, visando a formação de cidadãos que participem ativamente da sociedade em suas lutas pelas transformações sociais (ORDOÑEZ, 1993).

Esses elementos foram se constituindo como um campo epistemológico, metodológico e político tendo em vista a formação dos educadores ambientais de modo crítico, aberto e criativo (CIURANA, 2002). Esse processo foi denominado de ambientalização curricular, cujo termo ficou assim definido pela Rede Aces ${ }^{3}$ :

La ambientalización curricular es un proceso continuo de producción cultural tendiente a la formación de profesionales comprometidos con la búsqueda plenamente de las mejores relaciones posibles entre la sociedad y la naturaleza, atendiendo a los valores de la justicia, la solidaridad y la equidad, aplicando los principios éticos universalmente reconocidos y el respeto a las diversidades (JUNYENT; GELI, BAU, 2003, p. 21).

A ambientalização curricular abrange o conhecimento, os saberes e as habilidades dos educadores e educandos evidenciadas nas relações do homem com a sociedade e a natureza, por meio de atitudes éticas e sociais.

Na segunda reunião da Rede Aces, realizada em 2003 na Universidade Nacional de Cuyo (Mendonça, Argentina), as Universidades participantes elaboraram dez características constitutivas de um currículo ambientalizado, a saber:

1. Compromisso com a transformação das relações sociedade-natureza; 2. complexidade; 3. contextualização (local-global-local/global-local-global); 4. levar

\footnotetext{
${ }^{3}$ A Red Aces, denominada de Ambientalización Curricular de los Estudios Superiores (Ambientalização Curricular dos Estudos Superiores), é um projeto que teve como objetivo avaliar e diagnosticar os currículos das instituições superiores tanto na América Latina como na Europa. Ela foi constituída no âmbito do Programa América Latina Formação Acadêmica (Alfa) e envolveu onze universidades, sendo cinco da Comunidade Europeia: Universidade Autônoma de Barcelona, Universidade de Girona (Espanha), Universidade de Sannio (Itália), Universidade de Aveiro (Portugal) e Universidade de Hamburgo (Alemanha); e seis da América Latina: Universidade Nacional de San Luis (Argentina), Universidade Nacional de Cuyo (Argentina), Universidade de Pinar del Rio (Cuba), Universidade Estadual de Campinas (Unicamp), Universidade Estadual Paulista (Unesp) Rio Claro e Universidade Federal de São Carlos (UFSCar) (BAU, 2003, p. 9).
} 
em conta o sujeito na construção do conhecimento; 5. considerar os aspectos cognitivos e de ação das pessoas afetivos, éticos e estéticos; 6. coerência e reconstrução entre teoria e prática; 7 adequação metodológica; 8. espaços de reflexão e participação democrática, 9. ordem disciplinar, flexibilidade e permeabilidade; 10 . Orientação prospectiva de cenários alternativos (que se respeitem as gerações futuras) (OLIVEIRA JÚNIOR et al., 2003, p. 41).

O tema da ambientalização curricular se constitui em um campo profícuo de investigação, seja por meio da elaboração de teses e dissertações, de artigos divulgados em periódicos científicos ou na apresentação de trabalhos em eventos acadêmicos. Nesse contexto foi realizada a pesquisa, cujos resultados ora apresentamos, a partir das seguintes questões: a) os cursos da Universidade Federal de Rondônia, campus de Porto Velho, incorporam nos seus projetos pedagógicos, a temática ambiental?; b) a incorporação da temática ambiental pelos diferentes cursos pode ser compreendida como um processo de ambientalização curricular?; c) quais temas ambientais têm sido priorizados pelos cursos de graduação da Unir, campus de Porto Velho?; e d) como a temática ambiental tem sido desenvolvida pelos professores e coordenadores de curso de graduação da Unir?

A partir dessas questões, definiu-se o objetivo da investigação: analisar se os cursos da Universidade Federal de Rondônia (Unir), campus de Porto Velho, incorporam a temática ambiental nos seus projetos pedagógicos e identificar quais temas ambientais são priorizados por esses cursos.

\section{Delineamento da pesquisa}

A pesquisa caracteriza-se como de natureza qualitativa, do tipo estudo de caso, e os instrumentos utilizados para a coleta de dados foram a análise documental dos projetos pedagógicos e dos planos das disciplinas dos cursos de graduação que contemplam a temática ambiental, bem como a realização de entrevistas com os coordenadores e professores desses cursos.

Foram analisados 14 projetos pedagógicos e realizadas 37 entrevistas semidiretivas com os coordenadores e professores dos cursos de graduação do campus de Porto Velho pertencentes aos seguintes Núcleos: a) Núcleo de Ciências Humanas: cursos de Ciências Sociais, Pedagogia e História; b) Núcleo de Ciências e Tecnologia: cursos de Geografia, Ciências Biológicas, Química, Física, Engenharia Elétrica; c) Núcleo de Ciências Sociais Aplicadas: cursos de Administração de Empresas, Ciências Contábeis, Ciências Econômicas e Direito; e d) Núcleo de Saúde: cursos de Medicina e Enfermagem.

Para a análise dos dados utilizou-se a análise de conteúdo proposta por Bardin (2009), bem como as "características da ambientalização curricular" propostas pela Rede Aces (OLIVEIRA JÚNIOR et al., 2003).

\section{A temática ambiental na Unir}

A constituição do Ensino Superior em Rondônia ocorreu em 1973 com a vinda da Universidade Federal do Rio Grande do Sul (UFRGS) para a cidade de Porto Velho, por meio do Projeto Rondon para o oferecimento de cursos voltados para as áreas de Artes, Letras, Estudos Sociais e Ciências. As ações educativas foram realizadas através de um convênio com o Governo do Território do Guaporé (ALBUQUERQUE; MAIA, 2007). 
Em 1976, a Universidade Federal do Pará (UFPA) instalou em Porto Velho um Núcleo com os cursos de Ciências, Estudos Sociais, Letras, Pedagogia e Geografia. Tais atividades encerraram-se em 1985. Do mesmo modo, a Escola Superior de Educação Física do Pará mantinha em Porto Velho o curso de Educação Física, com o oferecimento de licenciatura curta (ALBUQUERQUE; MAIA, 2007, p. 54-67).

A Unir foi criada pela a Lei 7.011, de 8 de Julho de 1982, incorporando os cursos desenvolvidos pela Universidade Federal do Pará. Em seguida, desenvolveu uma política de expansão regional das atividades acadêmicas por meio do Primeiro Projeto Norte de Interiorização, com a finalidade de oferecer cursos novos de graduação e de implantar as condições necessárias para o desenvolvimento do ensino, da pesquisa e da extensão.

Em 2007, a Unir aderiu ao Projeto de Reunificação das Universidades Federais (Reuni) e ampliou os seus cursos tanto na sua sede administrativa, em Porto Velho, quanto os outros campi: Ariquemes, Cacoal, Guajará-Mirim, Ji-Paraná, Presidente Médici, Rolim de Moura e Vilhena. Antes da adesão ao Reuni, a Unir contava com 391 docentes, mas, com a abertura dos novos cursos, aumentou para 716 professores, 7.622 alunos de graduação e 438 técnicos no seu cômputo geral (UNIVERSIDADE FEDERAL DE RONDÔNIA, 2010).

Em sua estrutura de ensino, a Unir oferece 57 cursos de graduação presencial, quatro cursos de graduação à distância; dez mestrados acadêmicos; três mestrados profissionais e dois doutorados. Especificamente no campus de Porto Velho, denominado de José Ribeiro Filho, inaugurado em 1988, funcionam 29 cursos de graduação: Administração, Arqueologia, Artes Visuais, Ciências Biológicas, Ciências Contábeis, Ciências Econômicas, Ciências da Informação, Ciências Sociais, Direito, Educação Física, Enfermagem, Engenharia Civil, Engenharia Elétrica, Filosofia, Física, Geografia, História, Informática, Letras Espanhol, Letras Inglês, Letras Português, Matemática, Medicina, Música, Pedagogia, Psicologia, Química, Segurança Pública e Teatro. Conta atualmente com 367 professores e 3.769 alunos, (UNIVERSIDADE FEDERAL DE RONDÔNIA, 2010), e está localizada na BR 364, Km 9,5 (trecho Porto Velho-RO para Rio Branco-AC) ${ }^{4}$, conforme pode ser observado na Figura 1:

\footnotetext{
${ }^{4}$ Ao fundo, a Rodovia BR. 364, sentido Porto Velho-Guajará-Mirim e estado do Acre. Ela serve de deslocamento para os estudantes, funcionários e professores para chegar e sair da UNIR.
} 


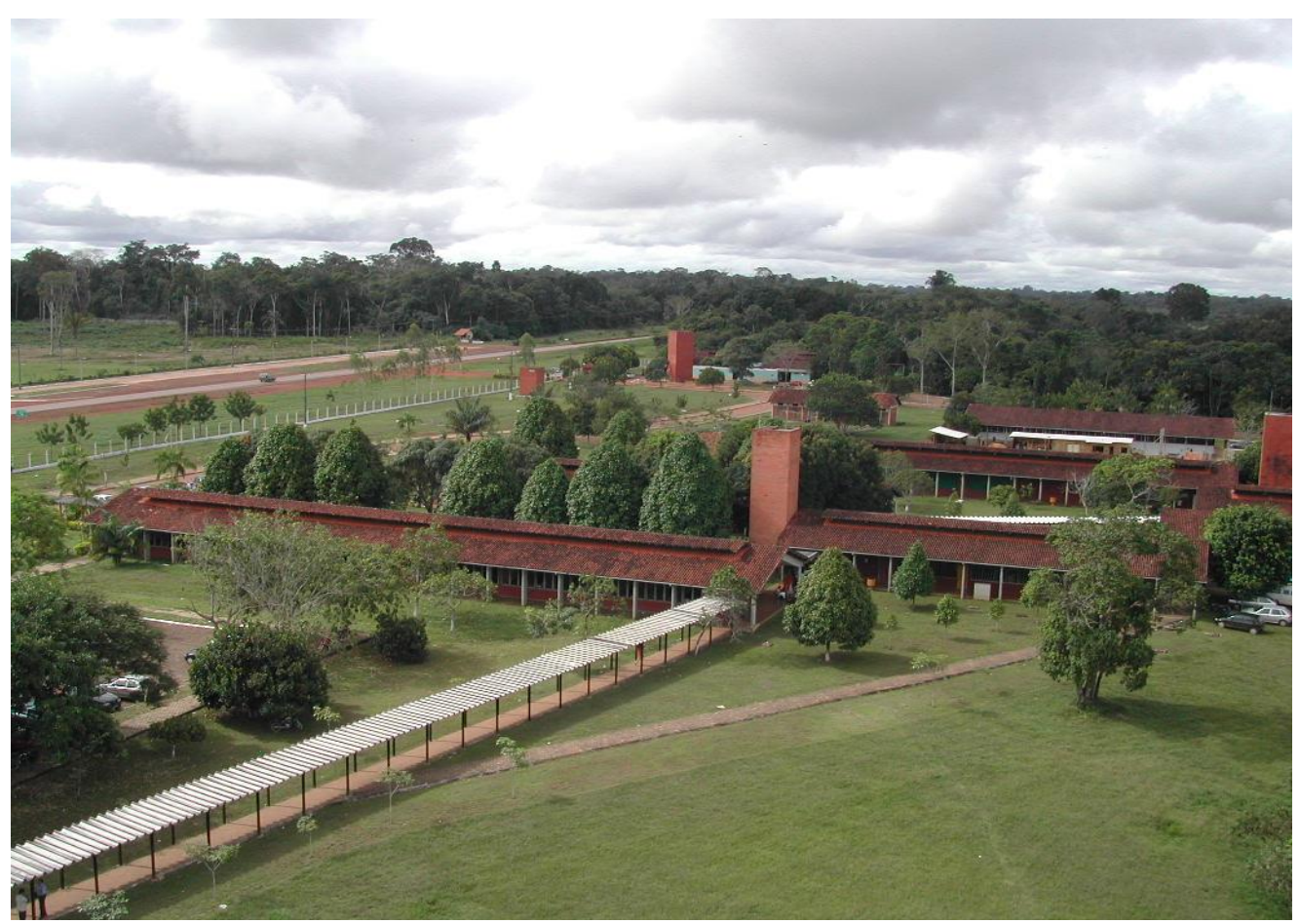

Figura 1 - Vista parcial dos blocos de sala de aula dos cursos de Graduação - campus de Porto Velho Foto: Luis Akeen (2008).

Por meio da análise dos projetos pedagógicos e dos planos de ensino concernentes às disciplinas e das entrevistas com os professores e coordenadores que trabalham com a temática ambiental dos cursos analisados, foram identificadas as seguintes disciplinas que abordam a temática ambiental, apresentadas no Quadro 1, a seguir:

\section{NÚCLEO DE CIÊNCIAS HUMANAS}

\begin{tabular}{|c|l|c|}
\hline Cursos & Disciplinas & Período \\
\hline & Educação dos Povos da Floresta & $4^{\circ}$ período \\
Pedagogia & Educação Ambiental e do Campo & $4^{\text {o }}$ período \\
\hline História & História da Amazônia & $5^{\circ}$ período \\
\hline Ciências Sociais & Tópicos Especiais em Ciência Política & $6^{\circ}$ período \\
\hline
\end{tabular}

\section{NÚCLEO DE CIÊNCIAS E TECNOLOGIA}

\begin{tabular}{|c|c|c|}
\hline Cursos & Disciplinas & Período \\
\hline Geografia & $\begin{array}{l}\text { Geografia Econômica } \\
\text { Climatologia } \\
\text { Hidrologia } \\
\text { Organização do Espaço Amazônico } \\
\text { Gestão Ambiental } \\
\text { Análise Ambiental } \\
\text { Educação Ambiental } \\
\text { Geografia de Rondônia } \\
\text { Geografia da Amazônia }\end{array}$ & $\begin{array}{l}2^{\circ} \text { período } \\
3^{\circ} \text { período } \\
4^{\circ} \text { período } \\
7^{\circ} \text { período } \\
8^{\circ} \text { período } \\
8^{\circ} \text { período } \\
8^{\circ} \text { período } \\
8^{\circ} \text { período } \\
8^{\circ} \text { período }\end{array}$ \\
\hline & $\begin{array}{l}\text { Biofísica } \\
\text { Liminologia } \\
\text { Ictiologia }\end{array}$ & $\begin{array}{l}2^{\circ} \text { período } \\
6^{\circ} \text { período } \\
7^{\circ} \text { período }\end{array}$ \\
\hline
\end{tabular}




\begin{tabular}{|c|l|c|}
\hline Ciências & Ecologia I & $4^{\mathbf{o}}$ período \\
Biológicas & Ecologia II & $5^{\mathbf{o}}$ período \\
& Biologia da Conservação & $8^{\mathbf{o}}$ período \\
& Ecologia da Amazônia & $8^{\mathbf{o}}$ período \\
& Ecologia de Campo & $8^{\mathbf{o}}$ período \\
& Tópicos Especiais de Ecologia & $9^{\mathbf{o}}$ período \\
\hline Química & Química Ambiental & 5 período \\
& Química dos Produtos Naturais & $8^{\mathbf{o}}$ período \\
\hline Física & Física Ambiental & $6^{\mathbf{o}}$ período \\
\hline Engenharia & Ciências Ambientais & $1^{\mathbf{o}}$ período \\
Elétrica & & \\
\hline
\end{tabular}

3. NÚCLEO DE CIÊNCIAS SOCIAIS APLICADAS

\begin{tabular}{|c|c|c|}
\hline Cursos & Disciplinas & Período \\
\hline Administração & $\begin{array}{l}\text { Ética Empresarial e Responsabilidade Social } \\
\text { Gestão de Agronegócios }\end{array}$ & $\begin{array}{l}4^{\circ} \text { período } \\
8^{\circ} \text { período }\end{array}$ \\
\hline $\begin{array}{l}\text { Ciências } \\
\text { Contábeis }\end{array}$ & $\begin{array}{l}\text { Planejamento e Controle Ambiental nas Organizações } \\
\text { Balanço Social e Ambiental das Organizações }\end{array}$ & $\begin{array}{c}7^{\circ} \\
\text { período } \\
8^{\circ} \\
\text { período }\end{array}$ \\
\hline $\begin{array}{l}\text { Ciências } \\
\text { Econômicas }\end{array}$ & $\begin{array}{l}\text { Economia Amazônica } \\
\text { Economia do Meio Ambiente } \\
\text { Sustentabilidade } \quad \text { Sócio-Ambiental } \\
\text { Desenvolvimento }\end{array}$ & $\begin{array}{l}5^{\circ} \text { período } \\
6^{\circ} \text { período } \\
8^{\circ} \text { período }\end{array}$ \\
\hline Direito & $\begin{array}{l}\text { Direito Ambiental I } \\
\text { Direito ambiental II }\end{array}$ & $\begin{array}{l}6^{\circ} \text { período } \\
7^{\circ} \text { período }\end{array}$ \\
\hline
\end{tabular}

4. NÚCLEO DE SAÚDE

\begin{tabular}{|c|l|c|}
\hline Cursos & Disciplinas & Período \\
\hline Medicina & Introdução à Saúde Coletiva & $9^{\circ}$ período \\
Enfermagem & Introdução à Saúde Coletiva & $1^{\circ}$ período \\
\hline
\end{tabular}

Quadro 1 - Disciplinas analisadas dos cursos de graduação da Universidade Federal de Rondônia, campus de Porto Velho, que abordam a temática ambiental

Fonte: Adaptado de Universidade Federal de Rondônia (2010)

O primeiro curso analisado foi o de Pedagogia, criado em 1982 com Licenciatura em Educação Infantil e Séries Iniciais do Ensino Fundamental, e oferece a disciplina de Educação dos Povos da Floresta. Os conteúdos trabalhados pelo professor são de natureza antropológica, caracterizados pela diversidade cultural e pelos valores presentes por meio da consciência ambiental. Caracteriza-se pelo multiculturalismo ambiental que se refere à identidade dos povos tradicionais abordando as questões no contexto da cultura amazônica. Entende-se que a temática do multiculturalismo ambiental foi evidenciada por meio de questões da justiça social evocada pelo professor. A crítica feita por este em seus conteúdos é de que os "inimigos da natureza" - como os madeireiros, os traficantes, os pecuaristas, os garimpeiros gananciosos e os políticos inescrupulosos - se aproveitam dos recursos naturais para obter maior enriquecimento.

No curso de licenciatura e bacharelado em História, criado em 1982, a temática ambiental está presente na disciplina História da Amazônia, com os conteúdos relacionados ao contexto histórico na formação amazônica, sobretudo, com o extrativismo da borracha. Discute o contexto histórico-econômico da produção e do extrativismo da borracha no Período Colonial 
e, assim, evidencia a dinâmica histórica vinculada à extração do ouro e das pedras preciosas nos estados do Acre, Amazonas, Pará e Rondônia. De acordo com Santili (2005, p. 144) "O extrativismo, cuja história é indissociável da história econômica, política e social da Amazônia, passou a ser visto como uma atividade capaz de associar conservação e valorização econômica dos ecossistemas florestais". Esta caracterização "sócio-econômica-cultural" é um indicativo de que a história ambiental não deve ser separada das suas singularidades sociais que compõem as particularidades do mundo amazônico (MARTINEZ, 2005).

O curso de licenciatura e bacharelado em Ciências Sociais, criado em 2003, objetiva uma formação para atender as questões sociais, políticas e culturais identificadas na realidade brasileira para conduzir as discussões e os debates na busca pelo conhecimento nas áreas de Sociologia, Antropologia e Ciência Política. As questões ambientais regionais são tratadas em disciplinas eletivas, como é o caso específico de Tópicos Especiais em Ciência Política, que teve como um título específico Integração Sul-América e o Planejamento Regional na Amazônia. Nessa disciplina, foram abordados conteúdos relativos ao desenvolvimento energético dos projetos das hidrelétricas, tais como: usinas das Usinas Hidrelétricas de Balbina (Pará), Tucuruí (Pará), Samuel, Jirau e Santo Antônio (Rondônia), bem como as políticas das ações governamentais referentes aos conflitos ambientais ocorridos na Amazônia, como a extração do garimpo, o desmatamento, o alagamento das terras dos ribeirinhos e dos indígenas.

Pode-se dizer, com isso, que os cursos pertencentes ao Núcleo de Ciências Humanas são trabalhados na interface com outras disciplinas e apresentam características do multiculturalismo ambiental na perspectiva da contextualização local/global/local/global-localglobal, bem como das questões relacionadas às seguintes características elaboradas pela Rede Aces: "levar em conta o sujeito na construção do conhecimento", "compromisso com a transformação nas relações sociedade-natureza".

Em relação ao Núcleo de Ciências e Tecnologia, foram analisados os cursos de: Geografia, Ciências Biológicas, Química, Física, Engenharia Elétrica e Engenharia Civil.

Os cursos de licenciatura e o de bacharelado em Geografia foram criados em 1982. A finalidade do curso de Licenciatura é o de formar professores com licenciatura plena para atuarem no ensino dessa área de conhecimento, e o bacharelado visa formar pesquisadores em Geografia. Propõe disciplinas centradas em três núcleos estruturais: o núcleo básico, o específico e o pedagógico. Nas disciplinas de Recursos Hídricos, Organização do Espaço Amazônico, Geografia de Rondônia, Geografia da Amazônia e Gestão e Análise Ambiental, que compõem o núcleo específico do curso de Geografia, podem ser identificados conteúdos ambientais

Os conteúdos do curso de Geografia abrangem características da ambientalização curricular, sobretudo com questões referentes ao espaço geográfico e a territorialidade, nos quais são analisadas as relações entre o homem e a natureza presentes nos eixos temáticos da Geografia Física e da Geografia Humana, representado pela visão crítica a respeito das especificidades sociais e culturais de Rondônia. A temática da Geografia cultural é caracterizada pelo estudo da cultura amazônica, principalmente a ribeirinha. A área da geografia física é caracterizada pelos estudos do clima, da temperatura, dos processos geológicos, do desmatamento, da poluição ambiental, da escassez nos recursos hídricos, da biodiversidade, da construção das hidrelétricas no rio Madeira, da constituição e da formação do espaço em que o ser humano vive.

Os aspectos da territorialidade e da espacialidade caracterizam-se pela realidade social e ambiental na Amazônia, entendidos como uma forma de investigar e estudar a temática ambiental visando à formação teórica e prática de licenciados e bacharéis em Geografia. Na licenciatura, desenvolvem-se conteúdos da Educação Ambiental na perspectiva da ética e da 
consciência ambiental, entendendo ser esta uma forma de pensar os contextos sociais e culturais e a forma de vida das comunidades urbanas e tradicionais na realidade amazônica.

O curso de Geografia tem procurado desenvolver a ambientalização curricular por meio da inserção de disciplinas para o desenvolvimento da temática ambiental referentes às relações homem, sociedade e natureza como um processo de formação e da aprendizagem evidenciando elementos significativos na teoria e na prática.

O Curso de licenciatura e bacharelado em Ciências Biológicas, criado em 1995, enfatiza a necessidade do trabalho com o meio ambiente, aliando a teoria à prática educativa para a formação ambiental, em relação à expansão agrícola, ao desmatamento, à expansão dos latifúndios e à reforma agrária em Rondônia. Na organização do currículo desse curso, a temática ambiental está contemplada nas seguintes disciplinas: Liminologia, Ecologia I ( $5^{\circ}$ período), Ecologia II ( $6^{\circ}$ período), Biologia da Conservação ( $6^{\circ}$ período), Ecologia da Amazônia ( $7^{\circ}$ período) e Ecologia de Campo ( $8^{\circ}$ período); bem como nas disciplinas: Botânica, Zoologia, Tópicos Especiais em Ecologia e Geologia.

As disciplinas de Biologia da Conservação e Ecologia de Campo abordam conteúdos significativos e se referem às unidades de conservação de Rondônia: a biodiversidade, a preservação, a manutenção do ecossistema em seu habitat natural, biodiversidade ambiental aliada à ecologia comportamental, à poluição ambiental à degradação pelo desmatamento na Amazônia e ao estudo dos impactos ambientais resultantes da construção das hidrelétricas no rio Madeira, demonstrando as relações sociais e culturais na relação homem, sociedade e natureza. A diversidade biológica e cultural amazônica exerce um papel significativo no ensino do curso de Ciências Biológicas. Este enfatiza que existe uma política de desmatamento pelos fazendeiros e madeireiros, prejudicial ao meio ambiente. A perda gradativa da biodiversidade da fauna e flora por meio da derrubada da floresta para as pastagens, a exploração dos minérios, como cassiterita e ouro e o plantio da soja, vem representando um grave problema para o meio ambiente e para a sociedade em geral (FERREIRA; VENTICINQUE; ALMEIDA, 2005, p. 157).

De acordo com a coordenação do curso de Ciências Biológicas, há uma preocupação do curso para que se aprofunde o conhecimento a respeito do bioma amazônico, pois "O biólogo daqui tem que ser diferenciado para a sua formação. Ele tem toda uma formação básica, adicional, complementar do nosso bioma, que é riquíssimo, diverso e complexo em termos de relações ecológicas". Nesse caso, a formação do biólogo deve contribuir para levá-lo a conhecer o bioma amazônico, os processos de conservação, bem como os impactos causados pela construção das hidrelétricas, de rodovias, de pavimentação de rodovias, e para a conservação da biodiversidade.

O trabalho educativo no curso de Ciências Biológicas revela quatro aspectos relacionados com a temática ambiental, a saber: a) uma formação básica tanto teórica como prática relacionada com o meio ambiente; b) elaboração e execução dos projetos tanto em nível técnico como experimental e pedagógico voltado ao desenvolvimento sustentável humano; c) compreensão da complexidade da vida, a diversidade dos seres vivos na manutenção do equilíbrio ecológico, especialmente com aqueles presentes na região amazônica; d) a formação do professor de Ciências Biológicas deve articular o conhecimento da Biologia com o meio ambiente, trabalho e consumo e a pluralidade cultural (UNIR, PROJETO PEDAGÓGICO DO CURSO DE BIOLOGIA, 2002). Esses perfis caracterizam-se por proporcionar uma formação acadêmica relacionada à temática ambiental. Por isso, a temática da preservação e conservação ambiental enfatizada nas disciplinas de Ecologia I e II, Biologia da Conservação e Ecologia de Campo amplia a aprendizagem dos acadêmicos do curso de bacharelado em Ciências Biológicas com temas voltados à realidade amazônica. 
O curso de Licenciatura em Química iniciado em 2002 tem um caráter específico de formar professores no Estado de Rondônia por meio de um trabalho com a biodiversidade amazônica. As disciplinas trabalhadas são a Química Ambiental e a Química de Produtos Naturais. A disciplina de Química Ambiental está mais centrada na temática da poluição em geral e, especificamente, nos poluentes tóxicos na água, principalmente aqueles ligados à indústria química. Do mesmo modo que o curso de Biologia, a temática da biodiversidade é trabalhada na disciplina de Química dos Produtos Naturais, cujo trabalho educativo está evidenciado na preservação dos ecossistemas provenientes da floresta amazônica diante dos seus compartimentos abióticos e bióticos, reforçando o compromisso de ensinar a temática ambiental com temas da biodiversidade amazônica, assim como os relacionados aos impactos ambientais causados pela contaminação dos agentes químicos na natureza.

Os cursos de Geografia, Biologia e Química, ao abordar os temas da espacialidade, da territorialidade e da biodiversidade ambiental, contemplam algumas características de ambientalização curricular elaboradas pela Rede Aces, tais como: contextualização localglobal-local/global/local/global-local-global, levar em conta o sujeito na construção do conhecimento; o compromisso com a transformação nas relações sociedade-natureza.

O curso de Licenciatura em Física, criado em 2004, procura desenvolver o conhecimento relacionado às demandas da sociedade rondoniense, como a energia sustentável, caracterizado nos diversos cenários que estão se constituindo devido às construções das hidrelétricas de Jirau e Santo Antônio. A disciplina trabalhada no curso é a Física Ambiental que contempla as discussões acerca da problemática energética. A discussão da temática ambiental nessa disciplina remete à complexidade da construção das hidrelétricas de Jirau e de Santo Antônio no rio Madeira, e os consequentes impactos sociais e ambientais abrangendo os meios aquático, terrestre, atmosférico e as relações entre o homem e a sociedade. Como um tema controverso, discute as relações da produção energética no Brasil e a necessidade da manutenção das comunidades tradicionais em seus espaços territoriais.

O curso de bacharelado em Engenharia Elétrica, oferecido a partir de 2007, surgiu da oferta de vagas do Projeto Reuni. Nesse curso, há uma disciplina denominada Ciências do Ambiente, na qual os estudos e as discussões pertinentes à relação homem - sociedade e natureza caracterizam-se pelas discussões em torno da construção das hidrelétricas quando envolve a complexidade ambiental na região amazônica. Essas relações dizem respeito ao contexto da realidade energética caracterizado pela dialética entre a sociedade e a natureza.

Os temas abordados referem-se aos conteúdos que tratam da realidade ambiental como um todo. Observa-se que o objetivo é o de estudar a realidade ambiental produzindo uma série de análises dos problemas ambientais do município de Porto Velho, dentre eles o saneamento público, a construção das hidrelétricas no rio Madeira e a energia elétrica no Brasil. Embora seja um curso novo na Unir, há indícios de que a temática ambiental está sendo trabalhada com conteúdos que retratam as relações entre o homem, o meio ambiente e a energia elétrica no contexto amazônico.

Como já apontado, os cursos do Núcleo de Ciências Sociais Aplicadas analisados foram: Administração de Empresas, Ciências Contábeis, Ciências Econômicas e Direito.

O curso de bacharelado em Administração, criado em 1980, caracteriza-se por desenvolver atividades voltadas para o planejamento, a organização e avaliação de empresas nas áreas de marketing, recursos humanos, produção, finanças, métodos e sistemas, cuja ênfase diz respeito à sustentabilidade e contempla os temas relacionados com a industrialização, o aumento de agrotóxicos, a cadeia produtiva, os impactos sociais, econômicos e ambientais na Amazônia. 
As questões presentes no discurso da sustentabilidade têm causado discussões contraditórias que enfatizam cada vez mais a rentabilidade econômica, trabalhada na disciplina de Gestão do Agronegócio. Essa disciplina contempla conteúdos voltados à cadeia produtiva na criação do gado e na agricultura, ou seja, o plantio da soja, a produção de leite, o desmatamento, os negócios da agropecuária, o uso de agrotóxicos, as queimadas e a poluição das bacias hidrográficas.

A disciplina Ética empresarial e Responsabilidade Social caracteriza o ensino com o desenvolvimento da consciência e da preservação ambiental nas relações entre o homem e a natureza diante da gestão empresarial. Essa condição implica em dizer que a abordagem da temática ambiental no curso de Administração de Empresas está muito pautada nas questões referentes ao desenvolvimento e à sustentabilidade ambiental. Os conteúdos trabalhados nessa disciplina analisam os impactos das grandes áreas de pastagens sobre o meio ambiente, bem como a gestão da rentabilidade proveniente da produção da carne, do couro e do leite para o consumo humano.

A temática ambiental é trabalhada no curso de bacharelado em Ciências Contábeis, também criado em 1980, por meio da disciplina Balanço Social e Ambiental das Organizações, evidenciando a demonstração contábil ambiental interna e externa que beneficia a preservação ambiental, cujo objetivo é o de planejar as atividades ambientais da empresa visando a orientação e o monitoramento do seu desempenho e sua responsabilidade ambiental/social. É trabalhada por meio da disciplina de Planejamento e Controle Ambiental nas Organizações com objetivo de desenvolver o processo de planejamento e controle das atividades ambientais da empresa tendo em vista também a orientação e o monitoramento do seu desempenho e sua responsabilidade ambiental/social. Os conteúdos enfatizam a relação entre os ativos e passivos ambientais (PFITSCHER, 2004) identificados como fundamentais para que os alunos aprendam a lidar com conteúdos de gestão ambiental com o objetivo principal de preservar o meioambiente.

O curso de bacharelado em Ciências Econômicas, oferecido desde 1980, tem como objetivo estudar o contexto econômico sustentável, no qual o economista dos dias de hoje é, sobretudo, um cientista social, que deve ser capaz de inserir-se na realidade da região amazônica. Há três disciplinas que trabalham com questões relativas ao desenvolvimento sustentável e à sustentabilidade socioeconômica e política: Economia Amazônica, Economia do Meio Ambiente e Sustentabilidade Socioambiental do Desenvolvimento. Os aspectos do desenvolvimento regional estão presentes na realidade rural e agrícola do estado de Rondônia e são trabalhados por essas disciplinas, contribuindo para a compreensão das complexas relações sociedade-natureza.

Os conteúdos dizem respeito aos avanços do capitalismo que afetam a estrutura social e econômica observada no contexto regional amazônico, evidenciando o modelo de desenvolvimento e seu reflexo na realidade ambiental. A análise contempla os processos capitalistas desde o campesinato até chegar ao desenvolvimento amazônico atual. A crítica feita por essa disciplina refere-se ao Programa de Aceleração do Crescimento (PAC) implantado pelo Governo Federal, em 2007, e da análise realizada a respeito da construção das usinas no rio Madeira e suas consequências para a realidade ambiental da Amazônia.

Especificamente em Rondônia, com o predomínio do gado e da soja, o lucro tem sido grande para os fazendeiros e agropecuaristas, com uma contínua exploração econômica da natureza com a consequente degradação do meio ambiente.

O curso de bacharelado em Direito da Unir foi criado em 1986, com objetivo de formar técnicos em ciências jurídicas. O interesse do curso é o de oferecer uma formação ética e cidadã para reforçar o compromisso de desenvolver os conteúdos jurídicos voltados para o meio 
ambiente na Amazônia. A aprendizagem relativa aos temas regionais demonstra a preocupação do curso de Direito em estudar as leis ambientais na sua execução e fiscalização.

Dentre as disciplinas com conteúdos relacionados com a temática ambiental estão o "Direito Ambiental I" e "Direito Ambiental II", que fazem parte da formação profissionalizante. Os conteúdos trabalhados nestas disciplinas referem-se à proteção e legislação ambiental relacionada às competências do Estado, da União e dos municípios, com prioridade aos conteúdos éticos e políticos. Do mesmo modo, eles se referem à proteção judicial e administrativa relacionada com os crimes contra o meio ambiente, a legislação da proteção ambiental das terras indígenas em que se destacam os contextos amazônicos em uma abordagem humanista.

A análise das disciplinas que contemplam questões relativas à questão ambiental nos cursos do Núcleo de Ciências Sociais Aplicadas revela uma preocupação com a sustentabilidade ambiental, podendo ser identificadas algumas características de um currículo ambientalizado, de acordo com a Rede Aces, a saber: complexidade; compromisso com a transformação das relações sociedade-natureza; contextualização (local-global-local/global-local-global); levar em conta o sujeito na construção do conhecimento; orientação prospectiva de cenários alternativos (que respeitem às gerações futuras).

Finalmente, os cursos do Núcleo de Saúde, o de bacharelado em Enfermagem, criado em 1988, e o de bacharelado em Medicina, criado em 2002, têm trabalhado com as questões relacionadas à saúde coletiva diante dos problemas sanitários que afligem a realidade rondoniense.

As questões ambientais estão voltadas para o reconhecimento das políticas públicas voltadas à relação homem - sociedade e meio ambiente, sendo esta tratada na disciplina de Saúde Coletiva em ambos os cursos. Nessa disciplina, são evidenciadas as implicações relacionadas com as questões ambientais, de modo que ocorre um reconhecimento das políticas públicas voltadas às questões relacionadas ao saneamento básico no contexto da cidade de Porto Velho.

Os professores e coordenadores entrevistados ressaltaram a importância de realizar um trabalho preventivo relacionado à saúde coletiva da população implicando nas questões ambientais. Desse modo, as doenças provenientes da falta de saneamento básico, como as verminoses, as doenças de pele, a asma e outras doenças pulmonares, por causa de ácaros e da fumaça, poderiam ser evitados se o homem tivesse uma relação de cuidado com o meio ambiente. Outras questões relacionadas à poluição da água pelo mercúrio nos rios amazônicos ressaltam que o homem não tem respeitado o meio ambiente e, portanto, tem levado a doenças crônicas. Desse modo, a mineração dos garimpos, sobretudo a da cassiterita e a do ouro, as atividades industriais, os resíduos de serviços de saúde, os curtumes, são os principais responsáveis pelas intoxicações e causas de doenças para a população.

De acordo com os relatos dos professores, a disciplina de Saúde Coletiva prioriza a saúde dos trabalhadores que está afetada pelas condições socioambientais, como o stress, a poluição sonora, a poeira e as queimadas, que trazem consequências diretas ao desempenho no trabalho. Tais questões implicam em considerar que os conteúdos trabalhados nos cursos de Medicina e Enfermagem contribuem para a ambientalização curricular, a saber: levar em conta o sujeito na construção do conhecimento; compromisso com a transformação das relações sociedade-natureza; contextualização (local-global-local/global-local-global); orientação prospectiva de cenários alternativos (que se respeitem às gerações futuras); complexidade.

\section{Considerações finais}


A partir dos dados coletados podem ser identificadas algumas características relacionadas ao processo de ambientalização curricular nos cursos de graduação da Unir em Porto Velho. Observa-se a característica da contextualização local-global-local e global-localglobal nas abordagens desenvolvidas pelos professores em temas que têm em comum a realidade amazônica, como a biodiversidade, os recursos hídricos, a conservação, a preservação ambiental e a justiça ambiental. Tais temas apresentam conteúdos trabalhados nos cursos de Ciências Biológicas, Geografia, e Ciências Sociais. Do mesmo modo, esta característica está presente nos cursos do Núcleo de Ciências Sociais Aplicadas, e pode ser observada na discussão da sustentabilidade ambiental na Amazônia, envolvendo conteúdos relacionados ao contexto regional, nacional e mundial dimensionados na área econômica e na administração dos negócios. Igualmente, nos cursos de Física e de Engenharia Elétrica, esta característica também pode ser observada tendo em vista a preocupação em enfatizar a temática da energia e da sustentabilidade da Amazônia que se reflete nas relações locais e globais.

A característica Complexidade foi observada nos cursos de Ciências Biológicas, Química e Geografia, que trabalham com as questões relacionadas à poluição ambiental, conservação, biodiversidade e à constituição da espacialidade amazônica, respectivamente.

A temática do multiculturalismo ambiental é trabalhada no curso de Pedagogia por meio de conteúdos antropológicos que descrevem as comunidades tradicionais, como os caboclos ribeirinhos, indígenas e seringueiros. Percebe-se que a Educação Ambiental poderia ser mais enfatizada no curso, pois este pode ser um caminho profícuo para a formação de professores das séries iniciais, particularmente em Rondônia.

No curso de História, embora, a temática ambiental não seja contemplada no Projeto Pedagógico, observou-se que, na disciplina de História da Amazônia, o professor tem trabalhado de modo interdisciplinar, com conteúdos referentes aos processos históricos da Amazônia relacionados à produção da borracha.

Observou-se no curso de Ciências Sociais uma flexibilização curricular que permite a inclusão da questão ambiental por meio de conteúdos referentes à relação homem, sociedade e natureza, como pode ser observado na disciplina Integração Sul-América e o Planejamento na Amazônia. Nela, desenvolvem-se conteúdos que integram a justiça ambiental com debates em seminários e pesquisas, considerando a realidade de Rondônia, sobretudo no município de Porto Velho, onde foram construídas as hidrelétricas de Jirau e de Santo Antônio no rio Madeira.

As temáticas dos recursos hídricos, os conflitos com a terra, as configurações espaciais advindas do processo migratório do Nordeste, Sul, Centro-Oeste e também do Norte, a construção das hidrelétricas no rio Madeira, a problemática do desmatamento e as questões climáticas, dentre outras, são exemplos de como o curso de Geografia da Unir tem se comprometido em desenvolver a ambientalização curricular.

O curso de Ciências Biológicas oferece várias disciplinas que enfatizam o processo de Ambientalização curricular com temas relacionados aos recursos hídricos e à poluição ambiental, sendo enfatizada a análise a respeito das bacias hidrográficas de Rondônia, sobretudo no rio Madeira, onde as atividades de garimpo ainda estão presentes. A preocupação está, ainda, em investigar a realidade do uso da terra. Os impactos ambientais produzidos pela exploração amazônica como conteúdos pertinentes no curso de Ciências Biológicas são fundamentais na ótica da proteção e preservação da natureza, da floresta amazônica, da fauna e da flora, enfim, da vida.

Os cursos de Ciências Biológicas e Química enfatizam questões sobre poluição ambiental relacionadas às fronteiras agrícolas, à exploração mineral realizada pelos garimpos de ouro no rio Madeira, à exploração da cassiterita na região de Ariquemes e, ainda, queimadas, desmatamento, poluição dos rios, aumento da produção do lixo e a falta de saneamento básico 
no estado de Rondônia.

Constatou-se que os cursos, objeto dessa análise, trabalham pesquisas no campo ambiental de forma isolada, separada do ensino. A nosso ver, a incorporação da pesquisa no ensino contribuiria muito para o desenvolvimento da aprendizagem, sobretudo porque a Unir oferece três mestrados nos quais a temática ambiental é pesquisada.

Observou-se que os cursos de Ciências Biológicas e Geografia, que possuem laboratórios, aproveitam em parte a estrutura destes para fins didáticos. Essa constatação foi feita a partir das entrevistas com os professores e coordenadores, que apontam para uma falta de estrutura, principalmente para a inexistência de laboratórios, considerando que estes seriam um caminho didático importante para o desenvolvimento de trabalhos envolvendo a tônica ambiental.

Os conteúdos relacionados à temática ambiental a respeito da saúde ambiental nos cursos de Enfermagem e Medicina desempenham um importante papel para prevenir, corrigir e controlar os riscos do ambiente que possam prejudicar a saúde coletiva e individual para a geração atual e as gerações futuras.

A análise dos quatro cursos do Núcleo de Ciências Sociais da Unir revela que eles apresentam algumas características de ambientalização em seus currículos e programas, representando, de certo modo, a preocupação em formar profissionais que atuem com responsabilidade em relação ao meio ambiente. Essa constatação pode ser observada com mais ênfase no curso de Ciências Econômicas que, após a sua reformulação, acrescentou disciplinas que contemplam a temática ambiental no projeto pedagógico do curso.

Desse modo, em que pese o fato de as discussões dos projetos pedagógicos estarem ocorrendo na Unir, sugere-se que os currículos dos cursos de graduação do campus de Porto Velho repensem os seus projetos pedagógicos com a finalidade de inserir mais conteúdos relativos à questão ambiental. Essa inserção poderia ocorrer por meio de disciplinas ou, ainda, de uma perspectiva interdisciplinar. Igualmente, e com uma maior ênfase, recomenda-se que os cursos que ainda não inseriram a temática ambiental possam fazê-lo gradativamente, como é o caso dos cursos da área de Saúde, como Educação Física e Psicologia, e os cursos de Letras Português, Letras Espanhol e Letras Inglês, com a perspectiva de desenvolver o processo de ambientalização curricular.

Desse modo, pode-se observar que os cursos analisados de licenciatura em Pedagogia, História, Ciências Sociais, Física, Química, Ciências Biológicas e Geografia poderiam desenvolver com mais ênfase os conteúdos relativos à educação ambiental, pois possuem como foco a formação de professores para que atuem de maneira efetiva nas questões ambientais. Essa constatação deve-se ao fato de que esses cursos não assumiram com determinação a temática ambiental no processo formativo. Por isso, constatou-se que esta, na Unir, necessita levar em conta a interdisciplinaridade com os conteúdos relacionados aos contextos naturais, sociais e culturais, tanto na teoria como na prática.

Em função da localização da Unir no espaço amazônico e, embora seja uma universidade nova e em fase de desenvolvimento, pode-se considerar, pelos dados encontrados, que a temática ambiental tem sido trabalhada pelos professores com a finalidade na melhoria do ensino e da aprendizagem voltada para a ética e a consciência ambiental. Portanto, a realização desta pesquisa - a primeira a respeito da ambientalização curricular nas universidades do norte do país - pode contribuir para a realização de novas pesquisas, bem como para análises mais efetivas e debates a respeito da inserção da temática ambiental na universidade. 


\section{Referências}

ALBUQUERQUE, E. S.; MAIA, M. B. R. A trajetória do ensino superior público em Rondônia. Porto Velho: Edufro, 2007.

BAU, E. A. Apresentación: Red Aces. In: JUNYENT, M.; CIURANA, A. M. G.; ARBAT, E. (Eds.). Ambientalización curricular de los Estudios Superiores: proceso de caracterización de la ambientalización curricular de los Estudios Superiores. Girona: Universitat de Girona; Red Aces, 2003. v. 2, p. 9-12.

BARDIN, L. Análise de conteúdo. Lisboa: Edições 70, 2009.

CIURANA, A. M. G. Introdução. Universidade, sustentabilidade e ambientalização curricular. In: BAU, E. A.; CIURANA, A. M. G. Ambientalización curricular de los Estúdios Superiores: aspectos ambientales de las Universidades. Girona: Universitat de Girona, Red Aces, 2002. v. 1, p. 15-18.

FERREIRA, L. V., VENTICINQUE E.; ALMEIDA, S. O desmatamento na Amazônia e a importância das áreas protegidas. Estudos Avançados, São Paulo, v. 19, n. 53, p. 157-166, jan./abr. 2005. Disponível em: 〈https://goo.gl/7YQHNB>. Acesso em: 30 mar. 2010.

JUNYENT, M.; GELI, A. M.; BAU, E. A. Características de la ambientalización curricular: modelo Aces. In: JUNYENT, M.; GELI, A. M.; ARBAT, E. (Orgs.). Ambientalización curricular de los Estudios Superiores: proceso de caracterización de la ambientalización curricular de los Estudios Superiores. Girona: Universitat de Girona; Red Aces, 2003. v. 2. p. 15-32.

LEFF, E. La formación ambiental en la perspectiva de la Cumbre de la Tierra y de la Agenda 21, en Universidad y medio ambiente. In: CONGRESO IBEROAMERICANO DE EDUCACIÓN AMBIENTAL, 1., 1992, Guadalajara, México. Anais... Guadalajara: Universidad de Guadalajara, 1993. p. 75-92.

MARTINEZ, P. H. Brasil: desafios para uma história ambiental. Nómadas, Bogotá, n. 22, p. 26-35, abr. 2005.

MERCADO, M. T B. Dimensión ambiental y curriculum universitário. In. ALBA, A. (Org.). $E l$ curriculum universitário: de cara al nuevo milenio. Ciudad de México: Universidad Nacional Autónoma de México, 1997. p. 212-219.

MERCADO, M. T. B. El cambio ambiental de las instituciones de educación superior: avances y retos. In: LÓPES HERNÁNDEZ, E. S.; GAUDIANO, E. G.; MERCADO, M. T. B. (Coords.). La profesionalización de los educadores ambientales hacia el desarrollo humano sustentable. Ciudad de México: ANUEIS, 2005. p. 101-118.

OLIVEIRA JÚNIOR, W. et al. As 10 características em um diagrama circular. In: JUNYENT, M.; CIURANA, A. M. G.; ARBAT, E. (Eds.). Proceso de caracterización de la ambientalización curricular de los estudios universitarios. Girona: Rede Aces, 2003, v. 2, p. 35-55.

ORDOÑEZ, E. Y. C. Educación ambiental y universidad. Cuardenos de Trabajo, Bogotá, n. 1, 1993. Serie Estudios Ambientales. 
PAVESI, A. A ambientalização da formação do arquiteto: o caso do Curso de Arquitetura e Urbanismo da Escola de Engenharia de São Carlos (CAU, EESC-USP). 2007. 199 f. Tese (Doutorado em Educação) - Universidade Federal de São Carlos, São Carlos, 2007.

PFITSCHER, E. D. Gestão e sustentabilidade através da contabilidade e controladoria ambiental: estudo de caso na cadeia produtiva de arroz ecológico. 2004. 252 f. Tese (Doutorado em Engenharia da Produção) - Universidade Federal de Santa Catarina, Florianópolis, 2004. Disponível em: <http://nemac.ufsc.br/visualizar/teseelisete.pdf>. Acesso em: 20 set. 2009.

SANTILI, J. Socioambientalismo e novos direitos. São Paulo: Peirópolis, 2005.

UNIVERSIDADE FEDERAL DE RONDÔNIA. Departamento de Biologia. Projeto Pedagógico do Curso de Biologia. Porto Velho: UNIR, 2002.

UNIVERSIDADE FEDERAL DE RONDÔNIA. Relatório de Gestão 2007-2010. Porto Velho: UNIR, $2010 . \quad$ Disponível em; http://www.proplan.unir.br/downloands/1560_347_relatorio_readequado_07_final_ti. doc>. Acesso em 10 abr. 2011. 